\title{
PRÁTICAS DE ENSINO DA LÍNGUA ESCRITA NA ESCOLA: UMA REFLEXÃO ACERCA DO SABER-FAZER DE PROFESSORAS DOS ANOS INICIAIS
}

\author{
SIRLENE BARBOSA DE SOUZA \\ Mestre em Educação pela Universidade Federal de Pernambuco, doutoranda em Educação na Universidade \\ Federal de Pernambuco, professora da rede estadual de ensino de Olinda/PE. \\ E-mail: sirlenesouza23@yahoo.com.br \\ ANDRÉA TEREZA BRITO FERREIRA \\ Doutora em Educação pela Universidade Federal de Pernambuco, mestra em educação pela Universidade \\ Federal de Pernambuco, pós-doutora pela Université Paris 8, Vincennes, \\ Saint-Denis, Paris/FR. Professora associada do Centro de Educação da Universidade Federal de Pernambuco. \\ E-mal: andreatbrito@gmail.com
}

\begin{abstract}
RESUMO
Este artigo tem como objetivo investigar as práticas de ensino da leitura e da escrita e os usos dos materiais escritos em salas de aula dos anos iniciais do Ensino Fundamental de duas professoras, no sentido de entender como tais práticas se relacionavam (ou não) com a dinâmica social da escrita, fora da escola (SOARES, 1998). Numa abordagem qualitativa e de cunho etnográfico (LÜDKE; ANDRÉ, 1986; BOGDAN; BIKLEM, 1982), realizamos observações das práticas de ensino da leitura e da escrita de duas professoras com gravações em áudio, registros em diário de campo e minientrevistas semiestruturadas antes, durante e após as nossas observações. Os resultados apontaram que as professoras, embora conhecessem as teorias e os discursos oficiais mais atuais, recorriam a vários caminhos teórico-metodológicos para dar conta dos seus objetivos ao ensinar a língua materna em suas classes. Verificamos, ainda, que as práticas escolares de ensino embora, ora se afastem mais, ora menos, dos usos da língua em situações do cotidiano, essas fazem com que a língua escrita na escola adquira uma "existência social" (ROCKWELL, 1985).
\end{abstract}

Palavras chave: Ensino da leitura e da escrita.Práticas pedagógicas.Usos da língua escrita.

\section{PRACTICES TO TEACH WRITING AT SCHOOL: A REFLECTION ABOUT ELEMENTARY SCHOOL TEACHERS' KNOWLEDGE}

\begin{abstract}
This research aims to investigate the teaching of reading and writing practices of two female teachers, and the use of written materials in classrooms in the early years of primary school, in order to understand the way these practices are related (or not) to social dynamics of writing outside school (SOARES, 1998). The research has a qualitative and ethnographic approach (LÜDKE; ANDRÉ, 1986; BOGDAN; BIKLEM, 1982) and was conducted by the observations of the two teachers' reading and writing instruction practices audio recorded, the registers on the field diary and the conduction of semi-structured interviews before, during and after the observations. The results show that the teachers, although they knew the theories and the most current official speeches about the theme, resorted to various theoretical and methodological approaches to accomplish their goals to teach their mother tongue in their classes. It was also observed that school teaching practices are sometimes distant and sometimes closer to the use of language in everyday situations which make the written language at school acquire a "social existence"(ROCKWELL, 1985).
\end{abstract}

Keywords: reading and writing teaching; pedagogical practices; uses of written language.

\section{Introdução}

Pesquisas realizadas por historiadores e estudiosos da língua (DARTON, 1990; BURKE; PORTER, 1993; CAVALLO; CHARTIER, 1998; BAKHTIN, 2000; HEATH, 1998; STREET 1993; CHARTIER, 2010; SOARES, 1998, 2006, entre outros), têm mostrado que ao longo dos anos 
e em todo o mundo, as práticas de leitura e de escrita têm passado por transformações decorrentes de mudanças ocorridas tanto no contexto político, como econômico e social. Tais mudanças têm alterado as formas de ler e de escrever dos indivíduos em cada sociedade, sendo essas "praticadas" e "ensinadas" em diferentes espaços, com finalidades diversas. No entanto, embora a leitura e a escrita configurem-se como a materialização de atividades próprias/comuns/peculiares do ser humano, estas não se constituem como atividades simples; elas também não acontecem da mesma forma, com os mesmos objetivos e fins, em grupos sociais e épocas diferentes. Nessa perspectiva, o ensino da leitura e da escrita tem se revelado, ao longo do tempo, como um dos grandes desafios dos sistemas escolares que tomam forma em diversas sociedades, a partir do século XIX.

No Brasil, a partir das décadas de 1980 e 1990, vivemos uma redefinição bastante marcante quanto aos objetivos do ensino da Língua Portuguesa em nossas escolas, o que veio a configurar-se em novas propostas curriculares e redimensionar o trabalho com a língua na escola, mudando o foco "de como se ensina", para questões relacionadas ao "como a criança aprende" e, que por conseguinte, tem influenciado e modificado as práticas pedagógicas.

Nesse contexto, as ideias construtivistas e a divulgação da teoria da psicogênese da língua escrita de Emília Ferreiro e Ana Teberosky (1985) tiveram muita influência na construção de novas propostas para o ensino da língua materna no país e trouxeram reflexões bastante significativas para o processo de ensino e de aprendizagem, atribuindo novos lugares aos indivíduos envolvidos nesse processo: o aluno passou a ser entendido como um sujeito ativo que está, a todo tempo, elaborando, construindo e reconstruindo hipóteses acerca da natureza e do funcionamento da língua escrita; seus conhecimentos prévios acerca do objeto de conhecimento passaram a ser considerados e tomados como ponto de partida no processo de ensino da leitura e a da escrita.

As mudanças nas concepções de língua/linguagem, a partir dos estudos de Bakhtin (2000), também contribuíram de forma relevante para esse processo de mudanças. Ao entender a língua como um processo dialógico-interativo e ao considerar a sua função comunicativa, o autor supracitado concebe a relação entre ouvinte e falante como um processo de interação "ativa", onde ambos os sujeitos nela envolvidos assumem papel ativo na interlocução, não sendo o "lugar" ocupado por ambos, fixado à priori, antes são resultantes da própria mobilização discursiva no processo geral da enunciação.

É nesse contexto de rupturas e mudanças que, também, em meados dos anos de 1980, começou a ser introduzido no cenário educacional brasileiro o termo "letramento", usado pela primeira vez por Kato em 1986 e, algum tempo depois, no ano de 1988, por Tfouni, ganhando status de termo técnico no léxico dos campos da Educação e das Ciências Linguísticas. 
No entanto, as mudanças paradigmáticas, resultantes desse conceito, apontado como “[...] estado ou condição de quem não apenas sabe ler e escrever, mas cultiva as práticas sociais que usam a escrita." (SOARES, 1998, p. 47), só passaram a ganhar uma maior visibilidade no final dos anos de 1990: a observação de fenômenos mais amplos externos à escola passou a ser considerado, permitindo a compreensão de que os aspectos referentes às condições socioculturais e históricos do educando, exercem influências no seu processo de aprendizagem. Sobre esses aspectos, a autora referendada defende que, uma vez que se propõe tratar do fenômeno da linguagem, é particularmente relevante considerar tanto a perspectiva sociopolítica que evidenciam os fatores externos (sociais, políticos, econômicos, culturais), como a perspectiva linguística, que engloba as ciências linguísticas e as concepções de linguagem que subjazem à proposta pedagógica de ensino.

Pensar a língua enquanto um processo histórico e sociocultural tem, no decorrer dos anos, também gerado mudanças nas práticas dos professores, que passaram a propor o ensino da língua materna em uma perspectiva de letramento, cujo termo emergiu em nosso país, da necessidade de se explicar algo mais amplo do que o domínio da "tecnologia da escrita".

Nesse sentido, passou-se a entender que a atividade de leitura e de escrita, "não é pura e simplesmente um conjunto de habilidades individuais; é um conjunto de práticas sociais ligadas à leitura e à escrita em que os indivíduos se envolvem em seu contexto social" (SOARES, 2006, p. 72).

Nessa perspectiva, Rockwell (1985), buscando analisar os processos de ensino e de aprendizagem dessas habilidades nas relações e nas práticas institucionais cotidianas nas quais os aprendizes se encontram imersos, destacou que não seria possível compreendê-los tomando por base apenas o processo individual (psicogenético), que defende que a criança aprende por meio de um processo complexo, único e autônomo, pois que o conhecimento que a criança constrói não é resultado apenas da internalização e/ou reflexo dos conhecimentos históricos que a escola seleciona e busca transmitir ao longo dos anos. Como bem coloca essa autora, "Dentro da escola os conhecimentos não existem 'em abstrato' para que as crianças o assimilem; antes, assumem determinadas formas e são 'dados' à criança para que 'faça alguma coisa' com eles, para que os use de alguma maneira.” (ROCKWELL, 1985, p. 86).

Nesse sentido, essa estudiosa (1985), nos chama a atenção para o fato de que os resultados advindos da pesquisa social apontam uma grande variedade, tanto histórica como social, dos conhecimentos presentes nas práticas de ensino e de aprendizagem da leitura e da escrita que fazem com que a língua escrita adquira uma "existência social”. É nesse sentido, pois, que Albuquerque (2002) dialogando com Rockwell (1985), nos esclarece que se o ensino da leitura e da escrita na escola tem 
como objetivo garantir que o indivíduo se torne um leitor e um produtor de textos autônomo e proficiente é preciso assegurar a todos os alunos - diariamente - a vivência de práticas reais de leitura e de produção textual, a fim de que os mesmos entrem em contato com os diferentes usos da língua e percebam o porquê e o para quê utilizam a escrita, aproximando assim, as práticas escolares vivenciadas e praticadas por ele, daquelas que fazem parte do seu cotidiano.

Diante da multiplicidade de problemas que temos enfrentado a respeito do ensino inicial da escrita e, certos de que não existe um único método que seja capaz de dar conta da complexidade que envolve o processo de alfabetização, pois que a aprendizagem não se dá por um único caminho nem é igual para todos os indivíduos, visto que os fatores histórico, social e cultural exercem influências significativas nesse processo, se faz necessário abrir espaço para a reflexão sobre a necessidade de se investir na construção de "um conjunto de estratégias" de ensino que permita ao educando adquirir o "estado ou condição" de sujeito alfabetizado e letrado, resultado da ação de ensinar e aprender as práticas sociais da leitura e da escrita e, assim, responder adequadamente às demandas sociais em que se encontra inserido.

É nessa perspectiva que, entendendo o cotidiano da escola como um espaço onde são fabricadas práticas singulares de ensino, a invenção do cotidiano descrito por Certeau pode nos ajudar a compreender como os professores "apreendem e (re) criam" em suas salas de aula a cultura que lhes é imposta; pode nos ajudar, ainda, a desvelar os fatores que influenciam e, por vezes, determinam a "fabricação" das táticas utilizadas por eles ao construírem as suas práticas de ensino com a língua escrita (CERTEAU, 1994; FERREIRA, 2005).

\section{Metodologia}

A pesquisa ${ }^{1}$ da qual resultou este artigo teve como objetivo investigar como tem acontecido o ensino da leitura e da escrita e os usos que são feitos do material escrito nas turmas dos anos iniciais do Ensino Fundamental. Para tal, observamos as práticas de ensino de 2 professoras que ministravam as suas aulas em turmas do $2^{\circ}$ Ano do ciclo alfabetizador em escolas da rede municipal de ensino das cidades do Recife e de Camaragibe, em Pernambuco. A coleta dos dados ocorreu no período compreendido entre os meses de agosto a outubro de 2013, totalizando um quantitativo geral de 12 aulas.

Nesse estudo, optamos pela perspectiva da pesquisa qualitativa de cunho etnográfico, por essa algumas características da abordagem qualitativa adotada nas últimas décadas, nos estudos rela-

\footnotetext{
${ }^{1}$ Essa pesquisa constituiu-se de um estudo piloto realizado para a construção dos dados da tese de doutorado intitulada "As práticas pedagógicas dos professores: a construção da escrita e os usos do escrito nos anos iniciais do ensino fundamental", ainda em andamento e com previsão de defesa para o primeiro semestre de 2016.
} 
cionados às Ciências da Educação, entre elas, a obtenção de dados descritivos, os quais são apreendidos no contato direto do pesquisador com a situação estudada, retratando desse modo, a perspectiva dos sujeitos que dela participam (BOGDAN; BIKLEM, 1982).

Para a coleta dos dados, fizemos a opção pela observação participante pelo fato de esta possibilitar "[...] um contato pessoal e estreito do pesquisador com o fenômeno pesquisado [...]" (LÜDKE; ANDRÉ, 1986, p. 26). Para tal, fizemos uso de gravação em áudio e de anotações no diário de campo, uma vez que tínhamos como pretensão conhecermos mais de perto a forma pela qual elas fabricavam suas práticas relacionadas ao ensino e ao uso da leitura e da escrita. Realizamos também minientrevistas não estruturadas (com questões abertas e fechadas), as quais foram realizadas com as docentes, antes e durante todo o período das nossas observações. A nossa escolha por entrevistas dessa natureza se deu por estas permitirem que o pesquisador venha a conhecer mais particularidades a respeito dos entrevistados, bem como fazer as adaptações na estrutura do roteiro e condução da conversa, quando estas se fizessem necessárias (LÜDKE; ANDRÉ, 2005).

\section{As professoras}

A professora Kelly ${ }^{2}$ ministrava as suas aulas em uma turma do $2^{\circ}$ Ano em uma escola da cidade do Recife e já estava no exercício da docência há 12 anos. Ela havia cursado Pedagogia e Pós-graduação em Psicopedagogia e possuía bastante experiência de ensino em turmas dos anos iniciais do Ensino Fundamental.

A professora Ana Maria também ministrava as suas aulas em uma turma do $2^{\circ}$ Ano, porém, em uma escola da cidade de Camaragibe, região metropolitana de Recife. Tinha formação em Letras, estava a 16 anos de exercício do magistério e, também possuía uma larga experiência de ensino em turmas dos anos iniciais.

A seguir, apresentaremos alguns resultados referentes à análise dos dados coletados nas salas de aulas das professoras investigadas, a partir da escolha de uma categoria que nos permitiu ter uma visão "mais detalhada" das suas práticas de ensino da leitura e da escrita e dos usos que faziam do material escrito em suas classes.

\section{Alguns Resultados}

Durante as nossas observações, pudemos verificar que as docentes recorriam a diferentes caminhos teórico-metodológicos ao propor o ensino da leitura e a leitura em suas classes e que as

\footnotetext{
${ }^{2}$ Salientamos que por opção das mestras, não fizemos uso de codinomes para identificá-las nesse trabalho.
} 
suas praticas havia uma "mescla" de saberes oriundos, tanto das suas experiências adquiridas no exercício do seu "mètier" como também, construídos e reconstruídos a partir do que vivenciaram nos encontros de formação continuada dos quais já haviam participado.

Nessa perspectiva, apresentaremos, a seguir, algumas atividades desenvolvidas pelas docentes que envolveram o ensino da língua escrita e o uso de materiais escritos por elas selecionados para esse fim.

\section{As atividades de ensino da leitura e da escrita e as suas relações com as práticas sociais}

Assim como Rockwell (1985), em nossas observações pudemos verificar que dentro das salas de aula das professoras observadas quase não existiram momentos em que a língua escrita não estivesse presente e/ou fosse tomada como objeto de ensino. Dados os objetivos pretendidos pelas docentes e, sobretudo, ao papel que é atribuído à instituição escolar em relação ao trabalho com a língua materna (ensinar a ler e a escrever), verificamos que as atividades de leitura e de escrita propostas por elas, ora se afastavam, ora se aproximavam mais daquelas vivenciadas e praticadas pelos alunos em outros espaços que ultrapassam os muros da escola. Nessa perspectiva, passaremos à amostra dos dados colhidos na sala de aula das duas professoras, separadamente.

\section{A professora Kelly}

Durante as entrevistas realizadas com a professora Kelly, ela nos relatou que antes de planejar as atividades com a língua materna a serem desenvolvidas com a sua turma, recorria sempre aos resultados dos testes diagnósticos que realizava com os alunos no início e no decorrer do ano letivo. Uma vez que, a maioria deles ainda se encontrava no processo de alfabetização, oscilando entre os níveis silábicos e silábico-alfabéticos, a docente disse que buscava priorizar as atividades de leitura e de escrita que possibilitassem aos discentes avançarem nas suas hipóteses de escrita e consolidarem a alfabetização, objetivo por ela "perseguido" durante todas as nossas investigações. Desse modo, pudemos ver a mestra fazer uso de materiais escritos variados, tais como o alfabeto ilustrado que havia afixado na parede da sala, livros de literatura, tarefas fotocopiadas, cartazes com escritas de palavras e textos produzidos coletivamente pelos alunos.

Em relação ao trabalho com a leitura, mais especificamente, verificamos que Kelly fez uso com bastante frequência do livro didático de Língua Portuguesa ${ }^{3}$ que ela e os seus alunos possuíam e que este servia como um importante "recurso" no momento em que ela pensava as suas aulas 
(planejamento). A professora nos relatou que os textos nele presentes eram tomados, muitas vezes, como ponto de partida para desenvolver as atividades de leitura com os alunos.

Desse modo, ao trabalhar com a leitura, a partir do manual referendado, a docente buscava explorar os conhecimentos prévios e as ideias e opiniões dos aprendizes acerca das temáticas abordadas nos textos, através de atividades de compreensão/interpretação oral, bem como as características estruturais e composicionais dos gêneros textuais abordados, além da finalidade e funcionalidade dos mesmos, a partir de exemplos de situações onde os mesmos são utilizados fora do contexto escolar. Verificamos, também, que as formas de vivenciar as atividades de leitura a partir desse material foram variadas: ora era a professora quem lia os textos presentes no livro (geralmente os textos mais longos), ora ela pedia que os alunos a realizassem, primeiramente de forma silenciosa e, em seguida, coletivamente e/ou acompanhando-a no desenvolvimento da mesma (geralmente a leitura dos textos mais curtos e os enunciados das questões dos exercícios).

O extrato da aula, Quadro 1, nos fornece um panorama da dinâmica desenvolvida por ela ao trabalhar com uma das atividades propostas pelo livro de Língua Portuguesa:

\section{QUADRO 1 - Estrado da aula - dia 12/08/2013}

\section{Aula ministrada no dia 12/08/2013.}

Após explorar uma atividade de escrita (SEA) no manual de Língua Portuguesa, Kelly pediu que os alunos o abrissem em outra página, por ela indicada:

P: Vocês vão abrir o livro na página 116, mas não vão escrever nada, vocês vão ler, vão apenas ler silenciosamente... (depois de alguns minutos, após os alunos realizarem a leitura solicitada, a mestra pede para que um aluno realizasse a leitura - uma história em quadrinhos da Turma da Mónica).

P: Agora Pedro vai ler o texto em voz alta para a toda a turma!

Pedro deu início à atividade e quando percebeu após a leitura de um trecho da história, que se tratava de uma pergunta, reiniciou a leitura do parágrafo e mudou a entonação da voz. Os demais colegas da classe, ao ouvilo, sem em que ele ou a mestra solicitasse, os demais responderam a questão.

Como boa parte da turma estava desconcentrada no momento da leitura, interrompendo várias vezes o colega que a estava desenvolvendo, por não estarem entendendo a leitura, Kelly, ao perceber esse movimento, fabricou uma "tática" para assegurar que o objetivo que ela tinha com a atividade, fosse alcançado.

P:Vocês precisam prestar bastante atenção, porque eu agora vou pedir para outro aluno continuar a leitura, depois outro, outro... E assim por diante! Tem que prestar atenção porque vocês não sabem a quem eu vou pedir pra ler!

Após esses momentos, Kelly também fez a leitura completa do texto e das questões de compreensão sugeridas pelo manual para que os alunos as respondessem oralmente. À medida que eles explicitavam as suas respostas, a docente ia registrando no quadro e lendo para toda a turma, buscando direcionar a atividade de modo que todos chegassem a um consenso sobre elas para, em seguida, as copiarem em seus cadernos.

Conforme podemos visualizar no fragmento de aula apresentado e com base no que observamos durante o decorrer da aula, verificamos que as atividades sugeridas pela mestra a partir do livro didático de Língua Portuguesa limitaram-se à leitura e à exploração do conteúdo presente 
no texto, sem buscar estabelecer qualquer relação com outros textos que circulam socialmente, não sendo proposta por ela, uma ampliação da discussão da temática nele abordada. Nessa mesma dinâmica, as atividades de compreensão também se limitaram às perguntas sugeridas pelo manual, que tinham como proposição o levantamento dos conhecimentos prévios dos alunos acerca da estrutura composicional do gênero (a forma de organização espacial, a exploração dos balões de fala e dos sinais de pontuação utilizados nos diálogos e a finalidade do gênero), ficando a cargo do professor refletir com os aprendizes sobre a temática que o texto propunha. Aos aprendizes, nesses momentos, Kelly solicitou, apenas, que respondessem as perguntas, primeiramente de forma oral e, depois, sob a forma de escrita, em seus cadernos.

A partir das observações das atividades de leitura desenvolvidas com o livro de Língua Portuguesa, percebemos que a docente parecia ter certa preocupação em dar "conta de responder" as atividades sugeridas por esse manual. Com base nas nossas observações, podemos inferimos que tal postura por ela assumida poderia estar relacionada a 2 fatores: (1) a sequência de atividades a partir do trabalho com um gênero e/ou um texto propostas pelo manual, contemplava aquele que era seu objetivo principal ao explorar a língua materna (o ensino e a aprendizagem do sistema notacional) e; (2) a "cobrança dos pais e, por vezes, da escola quanto ao uso desse material didático na sala de aula. Desse modo, pudemos perceber que, ao buscar no livro didático o assunto que abordaria naquele dia, ela parecia ter claro em sua mente que o mesmo deveria oportunizar a exploração do SEA, mesmo que esse não fosse o principal objetivo da atividade, conforme constatamos nas atividades que ela selecionou para trabalhar nesse manual.

Nessa proposição, acreditamos que, uma vez que a professora se limitava a explorar apenas o que era sugerido pelo livro didático, ela "perdia" ricas oportunidades de propor uma reflexão mais aprofundada sobre o uso da língua escrita dentro e fora do espaço escolar, estabelecendo, desse modo, uma relação mais próxima entre a situação vivenciada nos textos abordados e experenciadas pelos indivíduos, fora desse espaço.

Vale salientar que, ao enfatizarmos que Kelly "limitou-se" a trabalhar apenas o que era proposto no manual, não se constitui aqui uma crítica ao uso e às atividades propostos por esse material, pelo contrário! Compartilhamos da ideia de que o livro didático constitui-se como um importante "material de apoio" para o planejamento, a construção e o desenvolvimento das atividades "fabricadas" pelos docentes, bem como um importante referencial de material escrito para os alunos, visto que, muitas vezes esse é o "único" material de qualidade do qual o aluno tem acesso principalmente em contextos extraescolares. 
É interessante observar, ainda, que na condução da atividade anteriormente apresentada, a professora Kelly, ao perceber que nem todos os alunos estavam participando da mesma, recorreu ao seu repertório cognitivo e evocou um dos esquemas por ela já experimentados em outros momentos, conforme nos relatou, apoiando-se em proposições que julgava verdadeiras, legítimas (GOIGOUX, 2002), e o materializou em uma "tática" de ensino que pudesse dar conta de atingir aquele que era o seu objetivo naquele momento (verificar a fluência dos alunos na leitura). Podemos verificar nesse mesmo extrato de aula, que ela também buscou se posicionar como "modelo" de leitor para os seus alunos, realizando essa atividade após ter solicitado que os mesmos a fizessem (ainda que de forma implícita). Ao indagarmos sobre a razão dessa ação por ela posta em prática, podemos perceber claramente que esse não era um objetivo por pretendido, porém, ao ser questionada após alguns segundos, afirmou que geralmente realizava a leitura após os seus alunos a terem feito, por alguns motivos, entre os quais ela citou: garantir que todos os alunos entendessem o que o assunto tratado no texto, já que uma vez que boa parte dos seus alunos ainda se encontravam no processo, a leitura não era fluída, o que dificultava, portanto, a compreensão de todos acerca do que estava sendo lido, para que os discentes pudessem perceber as pausas que ela fazia diante dos sinais de pontuação empregados, a mudança na entonação da voz quando se tratava da troca dos personagens no diálogo e, ainda, para explorar os sons finais das palavras que rimavam, ajudando-os a refletirem que essas palavras que terminavam com os sons parecidos, geralmente se escreviam com as mesma letras no final.

Em relação ao trabalho com os livros de literatura, verificamos que as atividades de leitura realizadas, ao contrário do que foi proposto a partir do livro de Língua Portuguesa, tiveram como objetivo principal a exploração das temáticas e dos conteúdos neles abordados e que Kelly buscava, sempre que havia oportunidade, estabelecer uma relação mais direta com as vivências cotidianas dos alunos fora do espaço escolar, como nos mostra o fragmento da aula (Quadro 2):

\section{QUADRO 2- Estrado da aula - dia 06/08/2013}

Aula ministrada no dia 06/08/2013.

A mestra deu início à atividade mostrando aos alunos a capa do livro de literatura que ela havia lido para eles no dia anterior e questionando-os sobre o conteúdo da história.

P: Que história nós lemos ontem? Quem lembra o nome da história que eu li ontem?

A1: A piiiipa!

A2: E o balaaanço!

A3: Os brinqueeeedos!

A4: A caixa de brinqueeedos!

A5: O baú de brinqueeedos!

P: Isso! "O baú de brinquedos" é o nome do livro. As histórias que eu li foram "A pipa" e depois, "O balanço"! 
P: Quem lembra como era a história? Quem quer contá-la? (um dos alunos da turma se dispôs a fazer a leitura e, à medida que ia realizando a atividade, os demais colegas o auxiliavam acrescentando ou antecipando informações).

P: Do que é que esse livro tá falando?

A6: De brinquedos! De um baú cheio de brinquedos!

P: E do que mais?

A7: Da história de um baú que tem muitos brinquedos. E esses brinquedos, eles têm uma história... Também ensina como a gente pode brincar com eles!

A8: É tia! E também conta a história dos personagens... a história deles com os brinquedos e conta também que muitas crianças não conhecem eles, nem brincam com eles.

P: E vocês? Vocês têm muito brinquedos? Do que vocês mais gostam de brincar? Vocês já conheciam esses brinquedos? Por que vocês acham que as crianças de hoje não conhecem ou não gostam de brincar com esses brinquedos?

Os alunos expuseram suas ideias e opiniões buscando relacionar com as suas vivências e com informações que obtinham dos meios de comunicação (televisão e internet) e relatos de pessoas mais velhas com as quais conviviam fora da escola.

P: Muito bem, agora eu vou ler outro texto que está no mesmo livro que tem essa história que eu li ontem. Ela se chama "Um barquinho de papel”. Alguém já conhece essa história?

\section{T: Nããããão!}

P: Ok! Então eu vou ler agora e na próxima sexta-feira, vamos confeccionar um barquinho de papel.

A mestra deu prosseguimento à aula lendo o texto e fazendo pausas para explorar algumas estratégias de leitura, tais como predição, seleção de informações, inferências. Ao findar essa atividade, Kelly leu um outro texto desse mesmo livro (A bruxinha de pano), passou a perguntar aos alunos se eles haviam gostado do texto e o que haviam entendido da história. Após esse momento e nessa mesma dinâmica, a mestra leu um outro texto do mesmo livro ("A bruxinha de pano"), o explorou oralmente, buscou relacionar com situações vivenciadas pelos alunos em seus lares estabelecendo uma relação entre as formas de brincar antigamente e nos tempos atuais.

P: Que brinquedos dos que a gente leu as histórias na semana passada e hoje, que poderiam ser confeccionados por a gente, sem precisar comprar em lojas?

A1: O barquiiinho!

A2: A pipa também, tia!

A3: A pipa e o balanço também!

A4: Minha mãe sabe fazer boneca de pano!

A5: Todos, tia! Tudinho!

A mestra aproveitou a discussão para explorar, também como eram as relações entre as crianças nos tempos em que os pais dos seus alunos eram crianças, as mudanças nas paisagens, para discutir questões referentes à violência e, ainda, para conversar com os alunos sobre as relações que se têm estabelecido atualmente entre as pessoas, com a chegada e o avanço das tecnologias da comunicação. A mestra encerrou esse momento, informando aos aprendizes que até o final da semana concluiria a leitura de todos os textos do livro. De acordo com a transcrição apresentada, verificamos que Kelly, antes de trabalhar com o livro de literatura referendado, buscou trazer à memória dos alunos elementos da história que ela havia contado para os mesmos em uma aula anterior, com o objetivo de motivar e despertar a curiosidade dos mesmos acerca da história que ia ser lida. Assim, ao propor a atividade com o livro ela, inicialmente, explorou as informações presentes na capa para levantar os conhecimentos prévios dos discentes em relação à temática que seria abordada, bem como para explorar os papéis desempenhados no livro, pelo autor e ilustrador e editora que o havia produzido. No decorrer da atividade, Kelly também fez uso de algumas estratégias de leitura, sobretudo, daquelas que podiam sinalizar para ela se os alunos estavam compreendendo a história, para levá-los a fazer "previsões" sobre o seu final e estabelecer e, ainda, para fazer com que os alunos percebessem que o conteúdo tratado na história tinha relação com o que eles viam em seus lares, através das conversas das pessoas mais velhas, de reportagens 
apresentadas na televisão e em sites da internet, principalmente, no que diz respeito aos brinquedos apresentados no texto e os mais atuais. Esses momentos eram vivenciados de forma prazerosa e participativa pela maioria da turma, que se mantinha concentrada para escutar a leitura e para interagir com a professora, na descoberta de objetos até então, por eles desconhecidos.

Nos momentos em que o livro de literatura era o material escrito utilizado por Kelly para explorar a leitura, pudemos assistir à fabricação de uma prática de ensino com esse eixo didático que tinha como foco, assim como já citamos, levarem os alunos a refletirem sobre o que estava sendo discutido, oportunizando-lhes exporem suas ideias e opiniões, através de atividades de compreensão oral e também escrita, onde a mestra assumia o papel de escriba das ideias dos alunos, sem se preocupar em fazer com os mesmos chegassem a uma resposta que ela ou o livro didático, por exemplo, sugeriam que eles lhes dessem. Era nesses momentos, portanto, que a língua materna parecia "ganhar" uma função social, pois lhes falava sobre eles mesmos, sobre os outros, sobre a vida!

Nessa e em outras aulas por nós acompanhadas, pudemos observar na prática da mestra, o seu esforço em articular o ensino da tecnologia da escrita às práticas de sociais de leitura e de escrita. Assim como Soares (2010), concordamos que esse "movimento" constante na prática da mestra é de fundamental importância para que os alunos encontrem sentido nos saberes que são por eles aprendidos e apreendidos na escola, ou seja, que os saberes ensinados na escola a escola têm uma relação "estreita" com as suas vidas.

No que concerne às atividades de escrita, estas por sua vez, foram exploradas pela docente a partir da escrita de palavras e frases (essa última, em um quantitativo bem menor) com foco na aprendizagem do sistema de escrita alfabética e, geralmente, tinha nas atividades presentes do manual de LP o seu ponto de partida.

No tocante às atividades de compreensão escrita de textos, como a maior parte da turma ainda estava no processo de alfabetização, como já mencionamos anteriormente, ao escrever as respostas dos exercícios sugeridos pelo livro de Português, os alunos que já tinham uma "certa" autonomia na escrita, realizavam a tarefa individualmente e tinham a sua tarefa corrigida por Kelly também de forma individual. Os aprendizes que ainda estavam no processo de aprendizagem da tecnologia da escrita, essa atividade era realizada por eles oralmente e coletivamente com o auxílio da professora, cujas respostas por eles manifestadas, eram por ela anotadas na lousa, para que juntos buscassem um "consenso" entre elas e, em seguida, Kelly as registrasse no quadro para que os mesmos as copiassem em seus cadernos. Nesses momentos, também pudemos observar que a docente fazia uso da escrita das respostas aos exercícios para explorar a escrita das palavras, tanto no que diz respeito a alguns princípios do SEA, como também, para atender os demais alunos da classe que já estavam alfabéticos, propondo a reflexão sobre a escrita, a partir do ensino de algumas regras ortográficas.

Vejamos no extrato da aula, Quadro 3, uma de suas aulas que ela ministrou nessa perspectiva: 


\section{QUADRO 3 - Estrado da aula - dia 12/08/2013}

\section{Aula ministrada no 12/08/2103.}

Dando continuidade ao trabalho que estava realizando no livro didático de Língua Portuguesa, Kelly pediu que os alunos lessem o enunciado do $10^{\circ}$ quesito juntamente com ela, o respondessem oralmente e, em seguida, em seus manuais (a atividade era para escrever os nomes de alguns brinquedos e brincadeiras).

Alguns alunos ficaram em dúvida sobre a escrita de algumas palavras, como por exemplo, a letra final da palavra "carrossel":

A1: Tia, é com " $u$ " ou com "l”?

A2: Tia, carrossel se escreve com " $u$ " ou com "l" no final?

A3: Também não sei! (outros alunos manifestam a mesma dúvida).

P: Vocês acham que é com "u" ou com "l" (escreve a palavra no quadro).

T: Os alunos ensaiaram as suas respostas de forma bastante oscilante, mas a maioria concluiu que a palavra se escrevia com a letra " $u$ ", no final).

A4: É não tia, é com "l" com som de " $u$ "!

P: Ok! Que outras palavras terminam com "l" e têm som de "u"?

A4: Mel!

A5: Pastel!

A6: Animal! Sol!

P: Muito bem! Vejam só o nome do colega de vocês que eu tô escrevendo no quadro...

\section{PAULO}

Vamos separar as sílabas do nome dele (os alunos separam oralmente o colega em sílabas, batendo palmas para cada uma das marcações). A mestra foi até o quadro e fez a mesma marcação na palavra que havia escrito.

$$
\text { O "l" no nome de "Paulo" tem o mesmo som do "l" no final da palavra "carrossel"? }
$$

\section{T: Não!}

\section{P: Não! Não tem o mesmo som porque aqui ó, o "l" está entre vogais!}

Em seguida, ela deu continuidade à aula, escrevendo as respostas do exercício no quadro para que os alunos as copiassem em seus cadernos.

Com base na transcrição apresentada, podemos verificar que embora a atividade de apropriação desenvolvida por Kelly não tivesse sido pensada anteriormente, os seus objetivos em relação ao que pretendia que os alunos aprendessem, eram claros. Desse modo, pudemos perceber nessa aula, e em outras que acompanhamos que, ao buscar no livro didático o assunto que estaria abordando, ela parecia ter claro em sua mente que o mesmo deveria oportunizar a exploração do SEA, mesmo que esse não fosse o principal objetivo da atividade proposta pelo manual.

Vale salientar que, embora a professora tivesse conhecimento da heterogeneidade em relação aos níveis de escrita em que se encontrava a sua turma, não verificamos no desenvolvimento das suas aulas, a proposição sistemática de tarefas diferenciadas para dar conta de atender a "essas diferenças”, salvo algumas posturas assumidas pela mesma na condução das atividades, como por 
exemplo, no momento em que ela pediu que os alunos realizassem uma atividade para avaliar o nível de escrita em que os mesmos se encontravam (tal atividade havia sido solicitada pela Orientadora de Estudos do PENAIC ${ }^{4}$, do grupo do qual ela fazia parte). Nesses momentos, como a avaliação era feita individualmente com os alunos, a condução da atividade se dava de forma diferente: para aqueles que ainda estavam entre os níveis pré-silábicos, silábicos e silábico alfabéticos, Kelly lia o enunciado da tarefa em conjunto com os alunos, silabava as palavras, batia palmas para ajudá-los a fazerem as marcações das sílabas, lia os nomes das letras, marcava no papel a separação silábica, etc. Com os demais alunos que estavam em um nível mais avançado, ela pedia apenas que os mesmos tentassem ler o enunciado da tarefa e as palavras, para, em seguida, responderem as questões.

Diante do que por nós foi observado, pudemos constatar que poucos foram os momentos em que aos alunos foi solicitado que desenvolvessem atividades de escrita de textos, embora o próprio livro didático que ela usava como principal referência para planejar e desenvolver as atividades com a língua também trouxesse sugestões de atividades de produção de textos, propostas de forma encadeada com as tarefas que envolviam os outros eixos didáticos da língua, como a leitura e a oralidade. Ao término das nossas observações na sala de aula de Kelly, verificamos, ainda, que embora as atividades com a língua materna desenvolvidas tivessem um caráter estritamente escolar, afastando-se mais das práticas de leitura e de escrita vivenciadas pelos alunos em contextos extraescolares, nelas também se encontrava imbricada uma perspectiva de letramento, ainda que de forma secundária.

A partir das entrevistas, pudemos inferir que a mestra acreditava na proposta do "alfabetizarletrando", ou seja, de que o ideal seria ensinar os alunos a ler e a escrever, a partir dos usos sociais da leitura e da escrita e que ela tinha conhecimento dos discursos vigentes que tratavam dessas questões (àquele ano, ela estava participando do $1^{\circ}$ módulo de formação do PNAIC), mas "fabricava" as suas aulas de acordo com os objetivos que tinha para a sua turma (levar os alunos à aprendizagem do SEA), percorrendo um caminho já bastante conhecido e experimentado por ela nas outras turmas nas quais já havia lecionado e, também, a partir do que ela havia aprendido durante a sua formação inicial e nos encontros de formação continuada, filtrando nessas formações o que julgava importante ensinar e "possível” de fazer, para os seus alunos aprenderem.

Essa postura assumida por Kelly vem corroborar com as colocações de Chartier (2007) de que os professores, de posse das bases teóricas e dos encaminhamentos oficiais para o ensino, "filtra-os"

\footnotetext{
${ }^{4}$ Programa de Formação Continuada de Professores Pacto Nacional pela Alfabetização na Idade Certa Cf. http://pacto.mec.gov.br/o-pacto.
} 
a partir daquilo que eles entendem como pertinentes trabalhar e, dentro de suas condições de trabalho, como possível de fazer.

\section{A professora Ana Lúcia}

Na sala da professora Ana Lúcia, as atividades de leitura por ela propostas foram bastante diversificadas para atender aqueles que eram seus objetivos em cada momento e/ou em cada aula. Nesse contexto, presenciamos ela propor desde a leitura das letras do alfabeto que estavam expostas na parede da sala, da rotina e do calendário do dia, dos enunciados e das atividades presentes nos livros didáticos, das tarefas escritas na lousa, até os nomes dos colegas que estavam nas capas dos livros e cadernos, os textos presentes nos livros de literatura, revistas e jornais, entre outros materiais escritos. Também pudemos presenciamos todos os dias em que estivemos em sua classe, antes de dar início às atividades do dia, a mestra juntamente com os seus alunos montarem em um espaço que ficava no final da classe, o "Cantinho da Leitura", o qual era composto por diversos livros de literatura, revistas variadas (científicas, de moda, de venda de produtos, etc.), gibis, etc. Esse espaço era "visitado" pelos alunos, tanto para atender uma solicitação de leitura feita pela professora como, também, por iniciativa própria dos mesmos, quando estes terminavam de realizar as tarefas da classe pedidas pela docente e eram vivenciados por eles com bastante entusiasmo.

As atividades de leitura sugeridas pelo livro de Língua Portuguesa ${ }^{5}$, assim como presenciamos na sala da Professora Kelly, também foram bastante exploradas pela professora Ana Lúcia, que fez uso desse material didático, principalmente, para trabalhar a interpretação e a compreensão dos assuntos presentes nos textos. Desse modo, pudemos assistir a mestra criar várias táticas para dar conta desse e, ainda, de outros objetivos que ela possuía com esse eixo de ensino, entre eles, avaliar, através de atividades de leitura individual, coletiva e em voz alta, a fluência dos aprendizes na leitura, obtendo, assim, um feedback para que ela, com base nesses dados, pudesse pensar em "possibilidades" que ajudassem os seus alunos avançarem nesse aspecto.

É importante destacar que durante o desenvolvimento do trabalho com o que era sugerido pelo livro de Português, a docente não realizou "tudo", "da mesma forma" e na mesma "sequência" como era proposto por esse manual, pelo contrário! Podemos constatar que ela mudava a ordem das atividades, suprimia questões dos exercícios, acrescentava informações de forma oral em relação às características dos gêneros abordados, explorava os suportes onde os textos estudados poderiam ser encontrados, criava e recriava outras atividades com base naquelas propostas pelo manual, etc. Esses movimentos da professora vêm confirmar o ponto de vista de Chartier (2007), de que os professores selecionam nos materiais que lhe são sugeridos, as atividades possíveis de fazer e os 
assuntos que eles julgam pertinentes ensinar. Tais movimentos dialogam, também, com a perspectiva de Certeau (1985), no que diz respeito às manobras engendradas pelos indivíduos na fabricação de táticas que possam dar conta dos seus objetivos em cada momento.

Foi nessa perspectiva que, a partir da leitura dos textos e dos exercícios presentes no livro de Língua Portuguesa, pudemos assistir Ana Lúcia criar variadas táticas de ensino, antes e durante as aulas, como forma de ampliar os conhecimentos dos alunos acerca da temática que estava sendo abordada, buscando estabelecer, a todo o momento, uma relação entre os conteúdos presentes no texto com as vivências cotidianas dos educando fora da instituição escolar, atribuindo ao texto escrito, assim, uma função social.

Vejamos a condução de uma atividade realizada pela docente, em que ela fez uso desse material (Quadro 4):

\section{QUADRO 4 - Estrado da aula - dia 30/09/2013}

\section{Aula ministrada no dia 30/09/2013.}

Ana Lúcia, após escrever a rotina do dia com o auxílio da turma, pediu que os alunos abrissem seus livros de Língua Portuguesa na página solicitada e a acompanhassem na leitura do texto (a letra de uma música). Após realizar a leitura, a docente pediu que os alunos também a realizassem, chamando a a atenção dos discentes para a entonação da voz, ao ritmo na repetição da sequência das palavras e às rimas. Em seguida, elaescreveu o título da música no quadro e passou a explorar oralmente as características composicionais do gênero:

"A velha a fiar"

P: Muito bem! Vocês já conhecem esse tipo de texto, não é?

T: Ééééé!

P: Que texto é esse?

T: É uma múúúúúsica! Um poeeema!! (os alunos dividem-se ao darem a resposta)

P: Por que vocês acham que é uma música? O que tem nela que faz vocês acharem que é uma música?

A1: Porque eu já ouvi!

A2: Porque tem rima!

A3: Porque tá assim ó... assim... dividido em pedaços.

A4: Tem estrofes e tem versos, né tia?

P: Ah! Porque tem estrofes e tem versos... Muito bem! Agora vocês vão fazer o seguinte: Vocês vão no livro de vocês, no texto... Vocês vão enumerar os versos e as estrofes desse texto que a gente leu... Vamos lá! (os alunos passaram a enumerar os versos e as estrofes do texto, enquanto a mestra ia passando pelas carteiras dos mesmos para auxiliá-los na tarefa).

Em seguida, ela pediu para que os educandos circulassem no texto as palavras que ela iria ditar (ela dizia à turma a estrofe e nela, eles procuravam a palavra ditada).

P: Muito bem! A palavra "pau", em que verso ela está?

T: No Trêêês!

P: Isso! E qual a primeira letra do nome "pau”?

T: $P$ !

P: E a última?

T: $U$

P: Muito bem, agora vocês vão abrir o livro de vocês na página 82. Eu vou ler a atividade para vocês... vou ler o que é para vocês fazerem.

A mestra foi até o quadro e reproduziu a atividade sugerida pelo livro. Em seguida, leu a questão e pediu para os alunos indicarem o quadrinho da resposta correta para ela marcar.

P: E então? Qual dessas respostas é a correta? 
T: Transformar algo em fiiiio! (os alunos leem a resposta no quadro).

P: Muito bem! Então nós vamos marcar o quadrinho...?

T: Doooois!

P: Agora todo mundo vai ler o quesito 3. O que é que tá pedindo pra fazer?

Os alunos fizeram a leitura do enunciado solicitado por Maria Júlia e ela deu prosseguimento à aula pedindo que nessa mesma dinâmica, os alunos lessem também o enunciado do $4^{\circ}$ quesito. À medida que os alunos respondiam as questões oralmente, a docente buscava uma unidade nas suas respostas, as escrevia no quadro e dizia para eles as copiarem em seus livros. Como podemos visualizar no extrato apresentado, a leitura do texto foi realizada tanto pelos alunos como pela mestra, que aproveitou a similaridade entre os sons finais das palavras nos versos da música para explorar além do SEA, a entonação que precisaria ser dada na voz, para evidenciar as rimas. A partir desse texto, ela também sugeriu, oralmente, palavras para que os educandos encontrassem outras que terminassem "iguais" a elas. No tocante às características do gênero abordado, estas foram exploradas de forma tanto oral como escrita.

Verificamos na transcrição apresentada que Ana Lúcia, a partir das atividades de compreensão do texto, buscou estabelecer relações entre o assunto nele abordado, com situações cotidianas vivenciadas pelos indivíduos fora da escola trazendo para o debate, problemáticas atuais bastante relevantes (o cuidado e respeito pelos idosos), ampliando, desse modo, a discussão que estava proposta pelo livro didático.

Verificamos que no decorrer de toda a atividade com o texto referendado, a docentebuscava estabelecer relações entre o assunto abordado na música e as ações praticadas pelas pessoas mais idosas que pertencentes à família dos alunos ou de outras pessoas por eles conhecidas. Nesses momentos, os alunos mostravam-se bastante empolgados para interagir com a mestra e os demais colegas da classe, relatando as histórias de vidas de seus avós e de outras pessoas idosas com as quais conviviam e/ou conheciam.

Nessa mesma proposição, à medida que os discentes relatavam as suas experiências. Ana Lúcia ampliou a discussão instigando-os a explicitarem suas opiniões acerca dos maus tratos sofridos por essas pessoas e apontarem possíveis ações para resolucionar tais problemas, buscando aproximar as temáticas abordadas no texto e as questões levantadas durante a aula, dos assuntos que faziam parte do cotidiano das crianças, "imprimindo", através da criação das "táticas de ensino", explicitadas, um caráter de uso a esses escritos.

Ao questionarmos a docente sobre o uso do manual de Língua Portuguesa no planejamento e desenvolvimento das suas aulas com a língua materna, a mestra nos informou que as suas escolhas não eram feitas de forma aleatória, mas nesses momentos, buscava basear as suas escolhas 
considerando, principalmente, dois aspectos, não sendo, portanto, feitas de forma aleatória: (1) a possibilidade de dar continuidade ao trabalho com um gênero que já vinha trabalhando com os alunos, no caso da aula transcrita, o gênero "poesia", a partir de outro gênero bastante conhecido e do gosto dos educandos (música) e; (2) de os conteúdos dos textos sugeridos puderem atender aquele que era o seu objetivo principal para o ensino da língua materna na sua classe: trabalhar a leitura e a escrita, a partir de textos de circulação social e que tratassem de assuntos que fizessem parte do dia a dia dos discentes. É importante destacar, ainda, que o movimento inverso também era posto em prática pela mestra. Dito em outras palavras, as temáticas e os textos presentes nesse manual também se configuravam, em alguns momentos, como "ponto de partida" para que ela construísse o seu planejamento, selecionando a partir do que ele propos, o gênero a ser estudado, bem como as atividades orais e escritas a serem desenvolvidas com a sua turma.

No que concerne à língua escrita, observamos na classe de Ana Lúcia, os educandos fizeram uso da mesma para dar conta ainda de vários objetivos: copiar e responder nos cadernos e livros didáticos os exercícios solicitados pela mestra, anotar recados para os seus parentes, para fazer a agenda, escrever as atividades que deveria ser feitas em casa (tarefa de casa), responder as tarefas dos exercícios das outras disciplinas e, ainda, para fazer o controle dos bilhetes das rifas vendidas àquela época, para angariar dinheiro para a festa do Dia das Crianças. No tocante às atividades escritas de produção de textos, por sua vez, essas na maioria das vezes foram sugeridas pela docente como uma forma de materializar aquilo que havia sendo trabalhado e discutido com os alunos durante a aula, a partir de uma história lida ou contada por ela.

Nessa perspectiva, nós também pudemos ver em todas as aulas que estivemos na classe da professora, que as atividades por ela propostas apresentavam-se como uma sequência do que já vinha trabalhando com os eixos da leitura e da oralidade, quer tivessem elas o objetivo de produzir textos com os gêneros estudados, quer tivessem como pretensão auxiliar os alunos a avançarem em suas hipóteses de escrita, como nos mostra o extrato da tarefa sugerida por ela, (Quadro 5):

\section{QUADRO 5 - Estrado da aula - dia 30/09/2013}

\section{Aula ministrada no dia 30/09/2013.}

\section{Atividade de Português}

$1^{\circ}$ ) Você conheceu a cantiga "A velha a fiar". Agora faça o que se pede:

- Uma lista dos animais que apareceram na cantiga:

- Pesquise e anote 10 palavras com "lh":

- Retire do texto 10 palavras e encontre 1 palavra que rime com cada uma delas:

Após explorar de forma oral e escrita, individual e coletiva, a atividade presente no livro de Língua Portuguesa aqui já transcrita, a mestra foi até o quadro e, a partir do que estava proposto 
pelo livro, "reconstruiu" e criou outras atividades, a fim de dar conta daqueles que eram os seus objetivos naquele momento: explorar o ensino da tecnologia da escrita, conforme podemos visualizar nos quesitos $b$ e $c$ do exercício apresentado, e, produzir uma lista com palavras pertencentes a um mesmo campo semântico (nomes de animais), presentes no poema trabalhado. Mais uma vez as práticas de ensino de Ana Lúcia vêm corroborar com as colocações de Chartier (2010), que ao discorrer sobre as práticas de ensino, pontua que as mesmas são permeadas por apropriações, não ocorrendo por meio de um ato passivo de recebimento de algo pronto e acabado, mas, constituem-se em um processo ativo de “(re) construção” de práticas já existentes.

Ao analisarmos as práticas de ensino da leitura e da escrita de Ana Lúcia, percebermos que estas pareciam se aproximar mais da perspectiva dos usos sociais da escrita, ou seja, do ler e escrever dentro das práticas sociais, e que o trabalho com os textos não estavam presentes como um "complemento" das suas práticas de alfabetização, o que veio a confirmar aqueles que eram os seus objetivos para o ensino da língua materna na classe (a formação de leitores e escritores proficientes), conforme pontuou durante a entrevista que com ela realizamos.

Assim, ao trabalhar com a língua materna em sua classe, a docente buscava ter sempre como "ponto de partida" para o ensino da língua escrita "o texto", quer fosse ele explorado a partir de um livro de literatura ou sugerido pelo livro de Português.

\section{Considerações Finais}

Ao término das nossas investigações nas salas de aula das professoras, pudemos verificar que, embora a aprendizagem do SEA se constituísse como o principal objetivo que elas possuíam para os seus alunos, ambas buscavam aproximar as atividades com a língua materna das práticas de leitura e de escrita vivenciadas por eles em contextos não escolares, ora se afastando, ora se aproximavam mais, dos usos sociais da língua escrita. Observamos que para dar conta dos seus objetivos, ambas fizeram uso de materiais escritos diversos, o que oportunizava aos alunos perceberam que a língua escrita estava presente tanto em suportes caracterizados como "estritamente escolares", como o livro didático, por exemplo, como também naqueles encontrados por eles em seus lares e em outros espaços que ultrapassavam os muros da escola, embora esses objetivos fossem pretendidos por elas de forma "secundária".

Também a partir das nossas investigações, os resultados apontaram que há uma grande variedade tanto histórica, como social de conhecimentos no "fazer pedagógico", presentes nas práticas de ensino e de aprendizagem da leitura e da escrita. Esses movimentos postos em prática pelas professoras e explicitados pelas mestras nos momentos de conversa com a pesquisadora, re- 
velam uma "mescla" de saberes por elas postas em prática quando pensavam, planejavam e fabricavam as suas atividades de ensino com a língua escrita: os saberes práticos e da experiência, os saberes das formações inicial e continuada, a troca de experiências com os colegas de profissão e as próprias experiências enquanto alunas que foram.

Revelaram, ainda, que assim como pontuaram Ferreira e Leal (2010), as professoras, de posse dos textos do saber e cientes dos discursos mais atuais para o ensino da língua materna, não "descartam" os saberes por elas construídos e experenciados no decorrer do exercício da sua profissão, pelo contrário! Buscam conhecer essas "novas orientações" para, a partir delas, avaliar, melhorar, trocar, adaptar, ratificar, refazer, abandonar e reconstruir as suas próprias práticas pedagógicas.

Verificamos, ainda, que as práticas escolares de ensino embora ora se afastem mais, ora menos dos usos da língua em situações do cotidiano, essas fazem com que a língua escrita na escola adquira uma "existência social".

\section{Referências}

ALBUQUERQUE, E. B. C. de. Apropriações de propostas oficiais de ensino de leitura por professores: o caso do Recife. 2002. Tese (Doutorado em Educação) - Faculdade de Educação, Universidade Federal de Minas Gerais, Belo Horizonte, 2002.

BAKHTIN, M. Estética da criação verbal. Martins Fontes: São Paulo, 2000.

BOGDAN, R. C.; BIKLEM, S. K. Investigação qualitativa em educação: uma introdução à teoria e aos métodos. Porto, PT: Porto, 1994.

BURKE, P.; PORTER, R. Linguagem, indivíduo e sociedade: história social da linguagem.

Tradução Álvaro Luiz Hattnher. São Paulo: Ed. UEP, 1993.

CERTEAU, M. A invenção do cotidiano:1. Artes de fazer. Tradução Ephraim Ferreira Alves. Petrópolis, RJ: Vozes, 1994.

CAVAlLO, G.; CHARTIER, R. História da leitura mundo ocidental. In: CAVALLO, G.; CHARTIER, R (Org.). São Paulo: Ática, 1998.

CHARTIER, A.-M. Práticas de leitura e de escrita - história e atualidade. Belo Horizonte: CEALE/Autêntica, 2007.

DARTON, R. O beijo de Lamourette. São Paulo: Cia das Letras, 1990. 
FERREIRA, A. T. B. Os saberes docentes e sua prática. In: FERREIRA, A.; Albuquerque, E.; Leal, T. (Org.). Formação continuada de professores - questões para reflexão. Belo Horizonte: Autêntica, 2005.

FERREIRA, A. T. B.; LEAL, T. F. Formação continuada de professores: enfim, o que pensam e sugerem os professores? In: FERREIRA, A. T. B.; CRUZ, S. P. S (Org.). Formação continuada de professores: reflexões sobre a prática. Recife: Ed. UFPE, 2010. p.69-87.

FERREIRO, E.; TEBEROSKY, A. A psicogênese da Língua Escrita. Porto Alegre: Artes Médicas, 1985.

HEATH, S. B. Ways whit Words. Cambridge: Cambridge University Press, 1983.

KATO, M. No mundo da escrita: uma perspectiva psicolinguística. São Paulo: Ática, 1986. p.7. OLSON, David R. O Mundo no Papel: as implicações conceituais e cognitivas da leitura e da escrita. São Paulo, SP: Ática, 1997.

ROCKWELL. E. Os Usos Escolares da Língua Escrita. Cadernos de Pesquisa,n.52, p.85-95, 1985.

SOARES, M. Concepções de linguagem e o ensino da Língua Portuguesa. In: BASTOS, N. B.

(Org.). Língua Portuguesa: História, Perspectiva, Ensino. São Paulo: Ed. UC, 1998. p.53-60. . Letramento e escolarização. In: RIBEIRO, V. M. (Org.). Letramento no Brasil: reflexões a partir do INAF. 2001. São Paulo: Global, 2003. Práticas de Letramento e implicações para a pesquisa e para as políticas de Alfabetização e Letramento. In: MARINHO, M.; CARVALHO (Org.). Cultura escrita e letramento. Belo Horizonte: Ed. UFMG, 2010.

SOARES, M. Práticas de Letramento e implicações para a pesquisa e para as políticas de Alfabetização e Letramento. In: MARINHO, M.; CARVALHO (Org.). Cultura escrita e letramento. Belo Horizonte: Ed. UFMG, 2010.

STREET, B. Literacy in the Theory and Practice. Cambridge, UK: Cambridge University Press, 1984.

TFOUNI, L. V. Letramento e Alfabetização. São Paulo: Cortez, 2004. 